\title{
A nova camada média - Anton Pannekoek
}

Versão original: Der neue mittelstand. Pressekorrespondenz: Berlim, 16/6/1909.

Versão em inglês: International Socialist Review, october, 1909. Tradução de William E. Bohn. Disponível em:

http://babel.hathitrust.org/cgi/pt?id=njp.32101076886264;view=1up;seq=327 Acesso em 3 de abril de 2015.

\section{Tradução:}

\begin{abstract}
José Carlos Mendonça
Doutorando em Ciências Sociais (Universidade Estadual de Campinas - UNICAMP)

Pesquisador do Laboratório de Sociologia do Trabalho (LASTRO - UFSC)

jose.carlos@ufsc.br
\end{abstract}

Claus Henrique Bianco Castro

Graduado em Direito (Universidade Federal de Santa Catarina - UFSC)

Pesquisador independente

claushbcastro@gmail.com

Originais recebidos em: 24/04/2015

Aceito para publicação em: 07/07/2015

c) (1) $\Theta$

Atribuição - Uso Não-Come License. 


\section{Nota dos tradutores}

Neste trabalho optamos pelo equivalente "camada" ao invés de "classe" para a palavra inglesa Class. Esta escolha não é fortuita ou estilística. Trata-se de uma opção consciente que objetiva evitar confusão entre a categoria analítica marxiana das classes sociais, cara ao marxismo e ao autor do texto, e a prática sociológica da mera estratificação social que divide em segmentos (população, grupo social etc.) segundo um princípio hierárquico. A ser coerente com o princípio da estratificação neste caso, os "médios" sendo uma classe as outras duas seriam os "altos" e os "baixos", desaparecendo assim capitalistas e proletários. Ademais, como na regra de seus escritos em que sempre primou pelo rigor, no original alemão Pannekoek escolheu mittelstand ao invés de mittelklasse. Portanto nos parece uma opção do tradutor para a versão inglesa da qual discordamos. Em um texto que aborda exatamente este tema, nossa opção pelo termo "camada" se deu em beneficio exclusivo do rigor terminológico que resulta sempre, segundo nosso entender, em maior clareza de conteúdo e amplitude de fidelidade ao pensamento do autor.

$$
* * *
$$

\section{A nova camada média - Anton Pannekoek (1909)}

A camada média se situa entre os estratos mais altos e mais baixos da sociedade. Acima está a classe dos grandes capitalistas; abaixo, o proletariado, a classe dos trabalhadores assalariados. Ela constitui o grupo social de rendimentos intermediários. Contudo, não se distancia igualmente das outras duas classes. O pequeno burguês só se distingue do grande capitalista por uma questão de quantidade: ele possui uma quantia menor de capital, um negócio mais modesto. Portanto, a questão sobre quem pertence a essa camada de pequenos burgueses é de difícil resposta. Todo capitalista que sofre a concorrência de outros capitalistas ainda maiores acusa os que estão acima dele e clama por ajuda em nome da camada média.

Do proletariado, pelo contrário, o pequeno burguês está separado por uma diferença de qualidade: em sua função econômica. Mesmo que seu negócio e sua renda sempre sejam pequenos, ele é independente. Vive em virtude de sua propriedade sobre os meios de produção, como qualquer outro capitalista, e não da venda de sua força de 
trabalho, como um proletário. Ele pertence ao setor empresarial, que deve possuir algum capital para continuar empreendendo. Frequentemente ele mesmo emprega trabalhadores. Portanto, está nitidamente diferenciado da classe proletária assalariada.

Em épocas anteriores, esta camada de pequenos capitalistas constituía o corpo principal da população industrial. O desenvolvimento social, contudo, trouxe gradualmente sua destruição. A força motriz desse desenvolvimento foi a concorrência. Na luta pela existência, os capitalistas maiores, os mais aptos financeira e tecnicamente para sobreviver, excluíram os mais pobres e atrasados. Esse processo continuou em tal magnitude que, atualmente, a produção industrial se dá quase que exclusivamente em grande escala. Na indústria a pequena produção sobrevive somente em forma de reparos ou atividades artísticas especiais. Dos membros da camada média original um pequeno número alcançou a categoria dos grandes capitalistas. A grande maioria perdeu sua independência e se proletarizou. Para a geração atual, a camada média industrial existe apenas historicamente.

A camada a que me referi em meu primeiro parágrafo é a camada média comercial. Nós mesmos vimos, e ainda vemos, a decadência desse estrato social diante de nossos olhos. Está composto por pequenos comerciantes, lojistas, etc.. Apenas durante as últimas décadas os grandes capitalistas ingressaram no setor varejista. Somente recentemente inauguraram filiais e vendas por catálogo, expulsando assim os pequenos negócios ou forçando-os a uma coalizão. Se, recentemente, tem havido um grande lamento acerca do desaparecimento da camada média, devemos lembrar que é só a camada média comercial que está em questão. A camada média industrial se arruinou faz tempo e a camada média agrária tornou-se subordinada ao capitalismo sem perder os aspectos de independência.

Por conta do declínio da camada média, temos a teoria do socialismo na casca de noz. O desenvolvimento social que resultou nesse fenômeno fez do socialismo uma possibilidade e uma necessidade. Enquanto a grande massa da população fosse de produtores independentes o socialismo somente poderia existir como utopia de teóricos individuais ou pequenos grupos de entusiastas. Não poderia ser o programa prático de uma grande classe. Os produtores independentes não precisam do socialismo, não querem sequer ouvir sobre ele. Possuem seus meios de produção e esses são para eles a garantia de sustento. Mesmo a triste posição a que são forçados pela concorrência com os grandes capitalistas dificilmente pode torná-los favoráveis ao socialismo. Somente os faz mais ávidos em tornarem-se grandes capitalistas. Podem desejar, ocasionalmente, 
limitar a liberdade de concorrência - quiçá sob o nome de socialismo - mas não querem desistir de sua própria independência ou liberdade de concorrência. Consequentemente, enquanto existir uma camada média forte, essa atua como um muro de proteção para os capitalistas contra os ataques dos trabalhadores. Se os trabalhadores exigem a socialização dos meios de produção encontram nessa camada média apenas um oponente tão amargo como nos próprios capitalistas.

A decadência da camada média significa concentração de capital e crescimento do proletariado. O capital encara, consequentemente, um exército sempre crescente de oponentes e é apoiado por um número cada vez menor de defensores. Para o proletariado o socialismo é uma necessidade. Constitui o único meio de proteger o trabalho contra o roubo por uma horda de parasitas inúteis, o único baluarte contra a miséria e a pobreza. Como a grande massa da população vem cada vez mais a se consistir de proletários, o socialismo, além de ser uma necessidade, torna-se cada vez mais uma possibilidade. Assim, a proteção da propriedade privada é feita de forma cada vez mais débil e torna-se impotente contra as forças constantemente ascendentes do proletariado.

Não é preciso dizer, portanto, que a burguesia vê com preocupação o desaparecimento da camada média. O novo desenvolvimento, que inspira esperança e confiança no proletariado, enche a classe dominante de medo por seu futuro. Quanto mais rápido o proletariado, seu inimigo, aumenta em número, mais rápido a classe proprietária decresce, mais claramente a burguesia vê se aproximar sua condenação. Que fazer?

Uma classe dominante não pode renunciar voluntariamente à sua própria dominação. Essa dominação lhe parece o único fundamento da ordem do mundo. Deve defender essa dominação e só pode fazer isso enquanto tenha esperança e confiança em si mesma. Mas as condições reais não fornecem autoconfiança à classe capitalista. Assim, cria para si mesma uma esperança que não tem fundamento na realidade. Se essa classe alguma vez se deparasse com os princípios da ciência social perderia toda a fé em suas próprias possibilidades. Ver-se-ia como um velho déspota com milhões de vítimas perseguidas marchando sobre ele por todas as direções e lhe gritando seus crimes em seus ouvidos. Temerosamente se enclausura, fecha seus olhos para a realidade e ordena a seus mercenários que inventem fábulas para desvanecer a horrível verdade. E esse é exatamente o caminho da burguesia. Para não ver a verdade, designou professores para acalmar com fábulas seu espírito perturbado. São belas fábulas, que glorificam seu 
domínio, que deslumbram seus olhos com visões de uma vida eterna e dispersam suas dúvidas e sonhos do mesmo modo que muitos pesadelos. Concentração de capital? O capital está a todo momento sendo democratizado por meio da crescente distribuição de ações e títulos. Crescimento do proletariado? O proletariado ao mesmo tempo está ficando mais disciplinado, mais dócil. Decadência da camada média? Absurdo. Uma nova camada média está ascendendo para tomar o lugar da antiga.

É essa doutrina da nova camada média que desejo discutir em certo detalhe no presente escrito. A essa nova camada pertencem, em primeiro lugar, os professores universitários. Sua função é confortar a burguesia com teorias acerca do futuro da sociedade, e foi entre eles que essa fábula da nova camada média encontrou sua origem. Na Alemanha estavam Schmoller, Wagner, Masargh e um batalhão de outros que se dedicaram ao trabalho de elaborá-la. Explicaram que a teoria socialista sobre o desaparecimento da camada média era de pequena importância. Cada tabela de estatísticas mostrava que as rendas intermediárias continuavam quase tão numerosas como em tempos anteriores. No lugar dos produtores independentes em desaparecimento estavam aparecendo outros grupos da população. A indústria de grande escala demandava um imenso exército de profissionais intermediários: supervisores, especialistas, engenheiros, gerentes de departamento, chefes, etc. Eles formavam uma completa hierarquia de funcionários. Eram os oficiais e subalternos do exército industrial, um exército no qual os grandes capitalistas são os generais e os operários os soldados comuns. Os membros denominados profissionais liberais (médicos, advogados, escritores, etc.) também pertenciam a essa camada. Uma nova camada, então, em número constantemente crescente, que se dizia estar tomando o lugar ocupado anteriormente pela velha camada média.

Essa observação em si mesma é correta, ainda que de forma alguma seja de todo nova. Tudo o que há de novo sobre ela é sua exposição com objetivo de refutação das teorias socialistas sobre classes. Foi expressa claramente, por exemplo, por Schmoller a um Congresso Social Evangélico celebrado em Leipzig já em 1897. A plateia explodiu de entusiasmo ante as boas notícias e declarou em uma resolução: "O Congresso notou com prazer a tranquilizadora e cientificamente fundada convicção do orador de que o desenvolvimento econômico dos tempos modernos não conduz necessariamente à destruição de uma camada tão útil para o bem-estar da sociedade como a camada média". E outro professor declarava: "Ele nos encheu de otimismo pelo futuro. Se não é 
verdade que a camada média e a pequena burguesia estão desaparecendo, não nos obrigará a alterar os princípios fundamentais da sociedade capitalista.”.

O fato de a ciência ser mera serviçal do capitalismo não poderia se expressar de forma mais clara que nessas declarações. Por que essa declaração de que a camada média não está decadente é aclamada como tranquilizadora? Por que cria contentamento e otimismo? Será porque por meio dela os trabalhadores alcançarão melhores condições, serão menos explorados? Não, justamente o contrário. Se essa declaração for verdade, o trabalhador será mantido para sempre na escravidão por um exército permanente de inimigos. O que parece impedir sua libertação é aclamado como tranquilizante e otimista. O objeto dessa ciência não é a descoberta da verdade, mas a reafirmação de uma classe de parasitas cada vez mais supérflua. Não surpreende que entre em conflito com a verdade. Fracassa não só em sua negação do ensinamento socialista, como em amparar a classe capitalista. O conforto que proporciona não passa de autoengano.

A doutrina socialista acerca da concentração do capital não implica o desaparecimento dos rendimentos intermediários. Não tem nada a ver com as rendas relativas. Trata, ao contrário, das classes sociais e suas funções econômicas. Para nossa teoria, a sociedade não consiste em pobres, moderados e ricos, não consiste naqueles que possuem nada, pouco ou muito, mas sim em classes, em que cada qual exerce um papel distinto na produção. Uma classificação meramente externa, superficial, de acordo com os rendimentos, sempre foi um meio pelo qual os escritores burgueses confundiram as reais condições sociais e produziram obscuridade ao invés de clareza. A teoria socialista restaura a clareza e a exatidão científica ao concentrar a atenção sobre as divisões reais da sociedade. Tal método tornou possível formular a lei do desenvolvimento social: a produção em grande escala substitui constantemente a de pequena escala. Os socialistas sustentam que tendem a desaparecer cada vez mais, não os rendimentos intermediários, mas os pequenos produtores independentes. Essa generalização não é atacada pelos professores. Qualquer um familiarizado com as condições sociais, qualquer jornalista, funcionário público, qualquer pequeno burguês, qualquer capitalista sabe que é correta. Na própria afirmação de que a camada média está sendo resgatada por uma nova, ascendente camada reconhece-se especificamente que a anterior está desaparecendo.

Mas essa nova camada média possui um caráter completamente diferente da antiga. Que esteja entre capitalistas e proletários, e subsista com rendimentos médios, constitui sua única semelhança com a pequena burguesia de tempos anteriores. Mas essa 
era a característica menos essencial da camada pequeno burguesa. Em seu caráter essencial, em sua função econômica, a nova camada média difere completamente da velha.

Os membros da nova camada média não são autossustentáveis, unidades industriais independentes. Estão a serviço de outros, daqueles que possuem capital necessário para empreender. Em termos econômicos, a velha camada média consistia em capitalistas, mesmo que pequenos. A nova consiste em proletários, ainda que altamente remunerados. A antiga vivia em virtude de sua posse dos meios de produção. A nova se sustenta por meio da venda de sua força de trabalho. $\mathrm{O}$ caráter econômico dessa última não se modifica em nada pelo fato dessa força de trabalho ser de uma qualidade altamente desenvolvida, que tenha exigido uma onerosa formação acadêmica, e por isso, receba salários comparativamente altos. Não altera em nada o fato dessa força de trabalho ser principalmente de tipo intelectual, que dependa mais do cérebro que dos músculos. Na indústria moderna o químico e o engenheiro são tratados como meros trabalhadores assalariados. Suas forças intelectuais são exploradas ao limite do esgotamento justamente como as forças físicas do trabalhador comum.

Com a afirmação desse fato o palavreado professoral sobre a nova camada média se revela em toda sua tolice. É uma fábula, uma porção de autoengano. A nova camada média jamais poderá substituir a antiga enquanto proteção contra o desejo do proletariado por expropriação. Os pequenos capitalistas independentes de tempos anteriores sentiam-se interessados na manutenção da propriedade privada dos meios de produção porque eram eles mesmos proprietários de meios de produção. A nova camada média não tem o mais remoto interesse em manter para outros um privilégio do qual ela mesma não usufrui. Para ela dá no mesmo estar a serviço de um industrial particular, uma companhia acionista ou uma organização pública, seja comunitária ou estatal. Já não sonha em administrar um negócio independente. Sabe que permanecerá por toda a vida em posição subalterna. A socialização dos meios de produção não mudará sua posição a não ser para melhor na medida em que a libertará do capricho do capitalista individual.

Tem sido frequentemente comentado pelos escritores burgueses que a nova camada média possui uma posição muito mais segura que a antiga e, portanto, menos motivo para descontentamento. O fato de que as companhias acionistas destruam os pequenos empresários é uma alegação que não pode ser considerada contra suas muitas vantagens. Isso é realmente insignificante diante do fato de que aos pequenos 
empresários, depois de arruinados, são oferecidos cargos na companhia, aonde, via de regra, sua vida é muito mais livre de preocupações do que era inicialmente. (Hemburg). Curioso, então, que eles lutassem por tanto tempo, sacrificassem sua riqueza e se esforçassem ao extremo para se manter em suas velhas posições enquanto a todo tempo tal ancoradouro tentador os estava convidando! O que estes apologistas do sistema capitalista ocultam cuidadosamente é a grande diferença entre a dependência atual e a independência anterior. O homem de camada média de outrora sem dúvida sentia a pressão da necessidade, da concorrência, mas o homem da nova camada média deve obedecer a um senhor estranho, que pode despedi-lo arbitrariamente a qualquer momento.

Ora, é certamente verdade que aqueles que servem ao capitalista moderno como trabalhadores técnicos qualificados ou funcionários da companhia não são torturados pelas preocupações que esmagavam o mundo subjetivo do pequeno burguês de outrora. Frequentemente, também, seus ganhos são maiores. Porém, no que concerne à manutenção do sistema capitalista, são inúteis. Não é o descontentamento pessoal, mas sim o interesse de classe, a força motriz da revolução social. Em muitos casos, até o operário assalariado industrial de hoje está em uma posição melhor que o pequeno camponês independente. Apesar de os camponeses - em virtude da propriedade de seus pequenos pedaços de terra - terem interesse na manutenção do sistema de propriedade privada, ao passo que o operário assalariado exige sua destruição. O mesmo se dá com a camada média: os pequenos capitalistas oprimidos e descontentes, mesmo diante das desvantagens de sua posição, eram sustentáculos do capitalismo. E isso os empregados dos monopólios modernos, melhor posicionados e livres de preocupações, nunca serão.

Tal fato significa apenas que as frases professorais, pensadas para tranquilizar a burguesia com a ideia desta nova camada média e assim ocultar a tremenda transformação ocorrida, revelaram-se pura fraude, sem sequer a mais remota semelhança com a ciência. A declaração de que a nova camada ocupa a mesma posição que na luta de classes ocupou a pequena burguesia do passado demonstrou-se um equívoco inútil. Porém, no que se refere à real posição dessa nova camada, à sua função efetiva no organismo social, eu ainda mal toquei no assunto. ${ }^{1}$

\footnotetext{
${ }^{1}$ Devido à posição do intelectual no movimento socialista ter sido objeto de recente controvérsia, sintome obrigado a observar que aqui estamos tratando de um assunto completamente diferente. Nas discussões do partido a questão tem sido: Que papel podem exercer os indivíduos intelectuais dentro do movimento socialista? O problema que aqui temos sob consideração é: Qual o papel do conjunto dos intelectuais na luta geral de classes? (Nota do autor).
} 
A nova camada média intelectual possui uma coisa em comum com o resto do proletariado: é formada por não-proprietários, por aqueles que vendem sua força de trabalho e, consequentemente, não têm interesse na manutenção do capitalismo. Mais que isso, tem em comum com os operários o fato de que é moderna e progressista, que por meio do funcionamento das forças sociais reais torna-se constantemente mais forte, numerosa e importante. Por conseguinte, não é uma classe reacionária como era a antiga pequena burguesia. Não anseia pelos velhos bons tempos pré-capitalistas. Olha para frente, não para trás.

Mas isso não significa que os intelectuais se colocarão lado a lado com os operários assalariados em todos os aspectos, nem que, assim como o proletariado industrial, estejam predispostos a tornarem-se recrutas do socialismo. Para ser exato, no sentido econômico do termo, eles são proletários. Porém formam um grupo muito especial de trabalhadores assalariados, um grupo socialmente tão apartado dos proletários reais que formam uma categoria especial com uma posição especial na luta de classes.

Primeiramente, seu salário superior é uma questão relevante. Eles não conhecem nada da pobreza real, da miséria, da fome. Suas necessidades podem exceder sua renda e acarretar assim uma desconformidade que dá real significado à expressão "pobreza dourada" e ainda assim não os compele à necessidade imediata de atacar o sistema capitalista, como ocorre com os proletários reais. Sua situação pode incitar descontentamento, mas a dos operários é insuportável. Para eles o socialismo tem muitas vantagens. Para os operários é uma necessidade absoluta.

Somado a isso, deve-se recordar que este corpo de intelectuais e empregados industriais altamente remunerados divide-se em uma ampla e variada estratificação. Tais estratos são determinados principalmente pelas diferenças de renda e posição. Começamos pelo alto com os chefes de departamentos, superintendentes, gerentes, etc., e seguimos abaixo até os chefes e empregados de escritório. Estes últimos estão a menos de um passo dos operários com maior remuneração. Assim, em relação à renda e posição, de fato há uma queda gradual do capitalista ao proletário. Os estratos superiores têm um caráter definitivamente capitalista; os inferiores são mais proletários, mas não há nenhuma linha divisória nítida. Em razão dessas divisões os membros dessa nova camada média carecem da unidade subjetiva que torna a cooperação fácil para o proletariado. 
O estado de coisas precisamente descrito trava sua luta pela melhora de posição. É de seu interesse, como dos demais trabalhadores, vender sua força de trabalho pelo preço mais alto possível. Os operários o concretizam unindo forças nos sindicatos. Como indivíduos, são indefesos frente aos capitalistas, mas unidos são fortes. Sem dúvida esta casta superior de empregados poderia fazer mais para coagir os capitalistas se eles mesmos formassem um grande sindicato. Porém isso é infinitamente mais difícil para eles do que para os operários. Em primeiro lugar, por estarem divididos em uma infinidade de gradações e hierarquias, alinhados um acima do outro. Não se enxergam como camaradas e assim não podem desenvolver subjetivamente a solidariedade. Melhorar a condição de toda sua categoria não é uma questão de orgulho pessoal a esse indivíduo. É bem mais importante que lute pessoalmente pela promoção ao escalão superior. Para isso, é preciso que não caia em desgraça com a classe patronal por ter se oposto a ela em uma luta industrial. Assim, a inveja mútua dos níveis superiores e inferiores impede a ação cooperativa. Não é possível se desenvolver um forte laço de solidariedade. Dessa condição resulta que o empregado da camada em questão não coopere em grandes grupos. Eles se esforçam separadamente, ou somente uns poucos de forma conjunta, e isso faz deles covardes. Não sentem em si mesmos o poder que os operários obtêm da percepção do número. E logo, eles também têm mais o que temer do descontentamento dos patrões. Uma demissão para eles é uma questão muito mais séria. O operário está sempre à beira da inanição e assim o desemprego não o aterroriza tanto. O empregado de alta categoria, pelo contrário, possui uma vida comparativamente agradável, e é difícil encontrar uma recolocação.

Por todas essas razões, esta camada de intelectuais e altos empregados é impedida de instituir uma luta em fileiras sindicais pela melhora de sua posição. Somente nos estratos mais baixos, nos quais a maioria trabalha sob as mesmas condições e a possibilidade de promoção é difícil, há alguns sinais de um movimento sindical. Na Alemanha dois grupos de empregados dessa camada realizaram, tardiamente, um começo. Um desses grupos consiste nos capatazes das minas de carvão. Esses homens constituem uma categoria muito elevada de trabalho, pois além de supervisionar a indústria têm que fiscalizar os regulamentos projetados para assegurar as condições sanitárias e de segurança de trabalho. Condições especiais praticamente os obrigaram a se organizar. Os empresários milionários, em sua ganância por lucros, negligenciaram as recomendações de segurança em tal extensão que tornaram as catástrofes inevitáveis. Algo deveria ser feito. Até o momento a organização ainda é 
frágil e tímida, mas é um começo. O outro grupo está composto de mecânicos e engenheiros. Espalhou-se por toda Alemanha, tornou-se tão importante, de fato, a ponto de virar alvo de ataque dos capitalistas. Alguns patrões implacáveis exigiram que os homens desertassem da organização, e quando se recusaram foram demitidos. Até o momento o sindicato não foi capaz de fazer nada por essas vítimas a não ser apoiá-las, mas mesmo nisso já uniram forças contra a classe capitalista.

Para a causa do socialismo podemos contar com essa nova camada média ainda menos do que para a luta sindical operária. Por um lado eles estão situados acima dos operários como superintendentes, supervisores, chefes, etc. Nesses cargos espera-se que apressem os operários, para extrair o máximo deles. Assim, representando o interesse do capital em relação ao trabalho, eles assumem naturalmente uma posição de amarga inimizade com o proletariado e acham quase impossível estar ombro a ombro com ele numa luta por um único objetivo.

Além disso, um conjunto de ideias, particularmente de noções de si mesmos e de sua posição, tende a aliá-los aos capitalistas. A maioria deles provém de círculos burgueses, ou ao menos, pequeno-capitalistas, e traz consigo todos os preconceitos opostos ao socialismo. Entre os operários, tais preconceitos são desenraizados por seu novo ambiente, mas entre esses altos empregados intelectuais, são fortalecidos de fato. Os pequenos produtores tinham, por exemplo, como primeiro mandamento, a ideia de que cada um poderia lutar para superar a concorrência somente em virtude de sua própria energia. Em decorrência desse ensinamento permaneceu a noção de que o socialismo poria fim à iniciativa pessoal. Tal concepção individualista das coisas é fortalecida, como ressaltei, nos intelectuais por seu novo ambiente. Entre esses empregados especializados e frequentemente altamente posicionados, o mais eficiente às vezes se depara com a possibilidade de galgar as posições mais importantes.

Todos os habituais preconceitos burgueses se enraízam profundamente nesta camada, ainda mais porque seus membros se nutrem do estudo de teorias não científicas. Eles consideram verdade científica a opinião subjetiva, irracional, existente entre os pequeno-burgueses. Têm grande percepção de sua própria educação e refinamento, sentem-se elevados por sobre "as massas". Naturalmente, nunca lhes ocorre que os ideais dessas massas possam ser cientificamente corretos e que a "ciência" de seus professores possa ser falsa.

Como teóricos - sempre vendo o mundo como um amontoado de abstrações, trabalhando sempre com suas mentes e conhecendo nada ou pouco de atividades 
materiais - estão plenamente convencidos de que a mente controla o mundo. Essa noção os impossibilita compreender a teoria socialista. Quando veem as massas de trabalhadores e escutam falar de socialismo, pensam em um grosseiro "nivelamento por baixo" que poria fim às suas próprias vantagens sociais e econômicas. Em contraste com os operários, pensam em si mesmos como pessoas que têm algo a perder, e se esquecem, consequentemente, do fato de serem explorados pelos capitalistas.

Junte tudo isso e o resultado é que uma centena de causas separa esta nova camada média do socialismo. Seus membros não têm nenhum interesse independente que poderia conduzi-los a uma defesa enérgica do capitalismo. Porém seu interesse no socialismo é igualmente frágil. Constituem uma camada intermediária, sem ideais de classe definidos, e, por conseguinte, agregam à luta política um elemento que é instável e incalculável.

Nas grandes convulsões sociais, durante greves gerais por exemplo, podem às vezes se posicionar em prol dos operários e aumentar sua força. É mais provável que façam isso nos casos em que tal política esteja voltada contra o reacionarismo. Em outras ocasiões, podem estar ao lado dos capitalistas. Aqueles pertencentes aos estratos mais baixos simpatizarão com um socialismo "razoável", tal como o representado pelos revisionistas. Mas o poder que derrubará o capitalismo nunca pode proceder de nenhuma parte exterior à grande massa dos proletários. 